\title{
Insulin treated diabetes mellitus: causes of death determined from record linkage of population based registers in Leicestershire, UK
}

\author{
N T Raymond, J D Langley, E Goyder, J L Botha, A C Burden, J R Hearnshaw
}

Department of Epidemiology and Public Health, University of Leicester,

Faculty of Medicine, 22-28 Princess Road West,

Leicester LE1 6TP

N T Raymond

J D Langley

E Goyder

J L Botha

Department of Public Health Medicine, Leicestershire Health E Goyder

J L Botha

Department of Diabetes, Leicester General Hospital and Leicester Royal

Infirmary

A C Burden

J R Hearnshaw

Correspondence to: Mr N T Raymond.

Accepted for publication March 1995

\section{Abstract}

Study objective - Analyses of causes of mortality in people with diabetes using data from death certificates mentioning diabetes provide unreliable estimates of mortality. Under-recording of diabetes as a cause on death certificates has been widely reported, ranging from $15-60 \%$. Using a population based register of people with diabetes and linking data from this with causes of death data from another source is a viable alternative. Data from the Office of Population Censuses and Surveys (OPCS) are the most acceptable mortality data available for such an exercise, as direct comparison with other published mortality rates is then possible. Design - A locally maintained populationbased mortality register and all insulintreated diabetes mellitus cases notified to the Leicestershire diabetes register $(n=$ 4680) were linked using record linkage software developed in-house (Lynx). This software has been extensively used in a maintenance and update cycle designed to maximise accuracy and minimise duplication and false registration on the diabetes register. Deaths identified were initially coded locally to the International Classification of Diseases, 9th revision (ICD9), and later a linkage was performed to use official OPCS coding. Mortality data identified by the linkage was indirectly standardised using population data for Leicestershire for 1991. Standardised mortality ratios (SMR) were estimated, with $95 \%$ confidence intervals. Insulin dependent diabetes (IDDM) was defined as diabetes diagnosed before age 30 years with insulin therapy begun within one year of diagnosis. All other types were considered non-insulin dependent diabetes (NIDDM). Analyses were performed for the whole sample and then for the NIDDM subgroup. Results from these analyses were similar and therefore only whole group analyses are presented.

Main results - A total of 370 deaths were identified for the period 1990-92 inclusive - $56 \%$ were in men and $44 \%$ in women, median age (range) 71 years (12-94). Approximately $90 \%$ of deaths were subjects with NIDDM. Diabetes was mentioned on $215(58 \%)$ death certificates. The all causes SMRs were significantly raised for men and women for all ages less than 75 years. Ischaemic heart disease (ICD9 rubrics
410-414) accounted for 146 (40\%) deaths $41 \%$ of male and $38 \%$ of female deaths. Male and female SMRs were significantly raised for the age groups 45-64, 65-74, and $75-84$ years. Cerebrovascular disease (ICD9 rubrics 430-438) accounted for 38 (10\%) deaths and the SMR for women was significantly raised. For women the external causes of death (ICD9 rubrics E800E999) were also significantly raised overall and in age groups 15-44 and 45-64 years. This was not true for men, although numbers of deaths in this category were small for both men (4) and women (9).

Conclusions - Record linkage has been used successfully to link two local, population based registers. This has enabled an analysis of mortality in people with diabetes to be performed which overcomes the problems associated with using as a sample, death certificates where diabetes is mentioned. The mortality rates and SMRs estimated should more accurately reflect the true rates than would be possible using other methods. The persisting excess mortality identified for people with diabetes is of a similar magnitude and attributable to similar causes as has been reported elsewhere in population based studies.

\section{( $\mathcal{F}$ Epidemiol Community Health 1995;49:570-574)}

Comparative analysis of the mortality of people with diabetes is complicated by the problem of selecting and identifying the population at risk. Using death certificates that mention diabetes is unreliable as between $15 \%$ and $60 \%$ of these fail to mention diabetes as a cause. ${ }^{1-5} \mathrm{~A}$ hospital diabetes clinic based population may result in biased results as those attending may have more severe disease, ${ }^{46}$ particularly those with microvascular complications attending for diabetes care. A population based study, in a centre such as Leicestershire where most people with insulin treated diabetes are cared for by a centralised diabetes service, ${ }^{78}$ provides an opportunity to study a representative population of insulin-takers.

Previous studies have reported an overall excess mortality for people with diabetes. ${ }^{149-12}$ Ischaemic heart disease has been implicated as a particular contributor to excess mortality as has cerebrovascular disease. ${ }^{134612}$ There have been conflicting reports of cancer mortality. ${ }^{1341012}$ Different study methods and 
different samples make comparison of results between studies difficult. This study aimed to investigate the possibility of using record linkage and a population based register of people with diabetes to detect deaths, and to examine causes of deaths and patterns of excess mortality in the deaths detected.

\begin{abstract}
Methods
A population based register of people with insulin treated diabetes was established in Leicestershire during 1983-84, when the conversion to $\mathrm{U} 100$ insulin was implemented. This register was reinstated and computerised in 1986 using hospital and consultants' records, and data from diabetes specialist nurses, the family health services authority (FHSA), and district dietitians. In 1991 an ascertainment exercise using capture-recapture methods and patients themselves as an "independent" information source estimated the completeness of the register at $86 \%$. A record of people removed from the register because of death or migration is maintained. Register data for 1992 were used as denominators for estimating the mortality rates of people with insulin treated diabetes.

In Leicestershire there is also a locally maintained population based register of residents' deaths - the Leicestershire mortality list (LML). ${ }^{13}$ This register contains all data recorded on death certificates, including uncoded causes of death. Record linkage software ${ }^{1+4}$ (Lynx) developed within the Department of Epidemiology and Public Health and the Leicestershire Health Authority has been used extensively in a maintenance and up date cycle designed to maximise accuracy and minimise duplication and false registration on the diabetes register. The diabetes register, including deletions, was linked to the mortality register to produce a list of deaths. The linkage software used is a probabilistic record linker, which uses a phonetic name matching algorithm to link records despite misspellings or alternative spell-
\end{abstract}

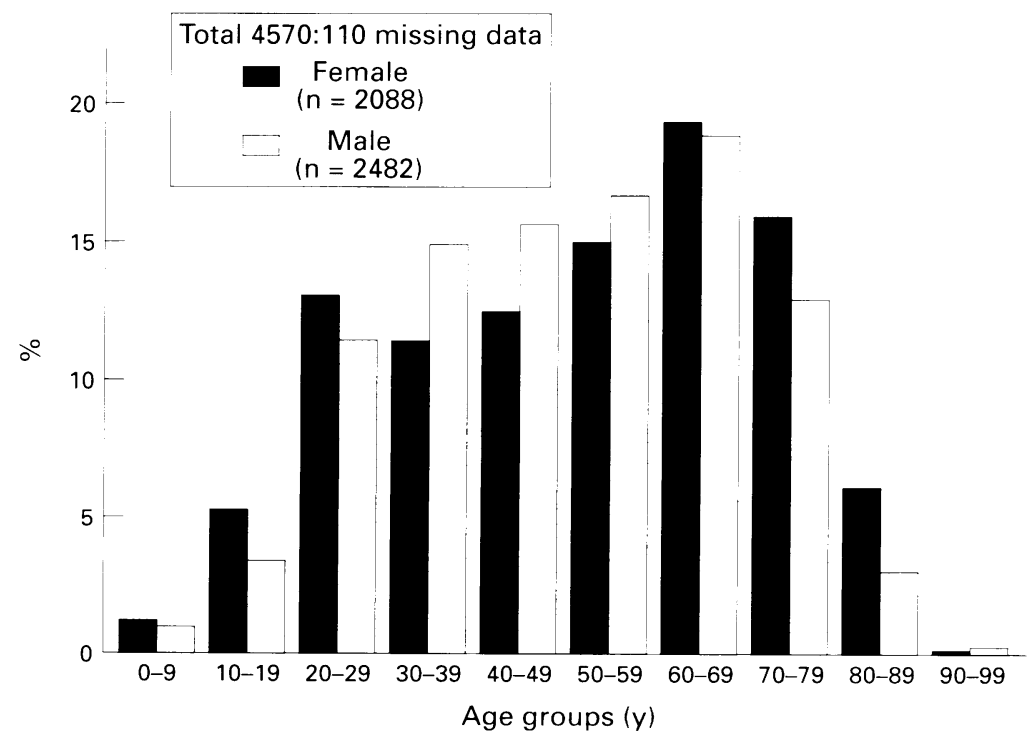

Figure 1 Leicestershire diabetes register (insulin treated diabetes), 1992, age-sex distribution. ings. We analysed deaths that occurred from 1 January 1990 to 31 December 1992, a three year period for which we were certain to have all deaths.

All causes of death mentioned on death certificates were available on computer as text strings. These were searched to check for mention of diabetes, hypoglycaemia, and renal failure to allow analysis of possible under-reporting of diabetes and examine associations between causes listed on death certificates and final underlying cause recorded. Causes of death were coded locally to ICD9 and later further record linkage was performed to incorporate OPCS coding. ${ }^{13}$ An analysis of the similarity of local and OPCS coding of the underlying cause of death was undertaken, and showed an overall agreement for $82 \%$ of death certificates. The main disagreement between local and OPCS coding was that local coders were less likely to assign diabetes as underlying cause of death (57 OPCS $v 22$ local). Analyses presented are all based on final OPCS coding.

Population and mortality data for Leicestershire for 1991 were used to standardise the data indirectly. Standardised mortality ratios (SMR) and 95\% confidence intervals (95\% CI) were estimated separatedly for men and women and within standard age bands. All cause mortality and deaths from diabetes mellitus (DM, ICD9 rubrics 250), ischaemic heart disease (IHD, ICD9 rubrics 410-414), cerebrovascular disease (CVA, ICD9 rubrics 430-438), neoplasms (ICD9 rubrics 140-239), and external causes (E-codes, ICD9 rubrics E800-E999) were examined independently.

To investigate the potential influence of the distribution of insulin dependent diabetes mellitus (IDDM) and non-insulin dependent diabetes mellitus (NIDDM) in the sample of deaths, IDDM was defined as diabetes diagnosed before age 30 and with insulin therapy started within one year of diagnosis. A comparative analysis of causes and age of death was performed by type and duration of diabetes.

Analyses were performed using the $S A S^{15}$ statistical package, calculating Fisher's exact tests, and $\chi^{2}$ tests of independence where appropriate. SMRs with $95 \%$ CIs were estimated using the Confidence Interval Analysis ${ }^{16}$ (CIA) microcomputer program.

\section{Results}

In 1992 the Leicestershire diabetes register included 4680 people with insulin-treated diabetes. The age-sex distribution is shown in figure 1 . A total of 370 deaths during the years 1990-92 were identified by linking the diabetes register and the local mortality list - $163(44 \%)$ were in females and $207(56 \%)$ in males. One female death at age 12 years from cystic fibrosis, was excluded from the main analyses as this was the only recorded death at age less than 15 years. The median age at death was 71 years (range 12-94).

Diabetes mellitus (DM) was mentioned on $215(58 \%)$ death certificates $-60 \%$ in 1990 , $55 \%$ in 1991 , and $58 \%$ in 1992 . For $57(15 \%)$ deaths diabetes was the underlying cause of 
Table 1 Mention of diabetes mellitus (DM) on death certificates in relation to underlying cause of death and sex.

\begin{tabular}{lccccc}
\hline Underlying cause of death & \multicolumn{2}{l}{ Men } & & Women \\
\cline { 2 - 3 } & No of certificates & Mention of DM (\%) & & No of certificates & Mention of DM (\%) \\
\hline Cerebrovascular disease & 16 & $10(63)$ & 22 & $17(77)$ \\
Diabetes & 32 & $1(25)$ & 25 & $25(100)$ \\
External causes & 4 & $41(48)$ & $9(31)$ & 61 & $4(44)$ \\
Ischaemic heart disease & 29 & $18(44)$ & 22 & $40(66)$ \\
Neoplasms & 41 & $111(54)$ & 23 & $5(23)$ \\
All other causes of death & 207 & 162 & $13(57)$ & $104(64)$ \\
All causes of death & &
\end{tabular}

death. Most mentions of diabetes were in part ii of the death certificate $(167(78 \%)$ v 48 $(22 \%)$ in part $\imath)$. Where diabetes was mentioned in part $i$, the underlying cause of death was significantly more likely to be ascribed to diabetes than when it was mentioned in part ii (34 $(71 \%) v 23(14 \%)$; Fisher's exact test, two-tail $\mathrm{p}<0.001)$.

Women were significantly more likely to have DM mentioned than men $(65 \%$ v 54\% respectively; Fisher's exact test, two-tail $\mathrm{p}=$ $0 \cdot 0428$ ) and the rate of mention of DM also varied in relation to the cause of death (table 1). DM was more likely to be mentioned on death certificates of those aged 85 and older than any other age group $(85+80 \%, 75-84$ 57\%, 65-74 59\%, 45-64 57\%, 15-44 38\%), although the differences were not statistically significant.

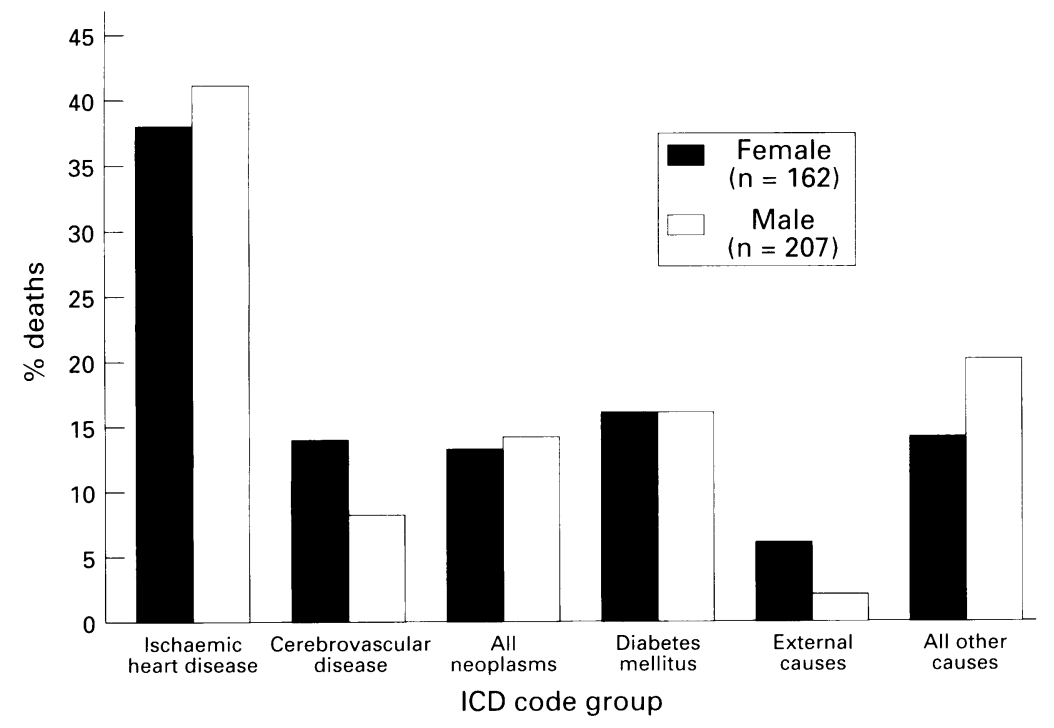

Figure 2 Distribution of underlying causes of deaths 1990-92 inclusive $(n=369)$.

Table 2 Age and sex specific standardised mortality rates (SMRs) for all causes of death

\begin{tabular}{|c|c|c|c|c|}
\hline Age group & Observed deaths & Expected deaths & $S M R$ & $(95 \% C I)$ \\
\hline \multicolumn{5}{|l|}{ Women: } \\
\hline $15-44$ & 6 & $1 \cdot 26$ & $4 \cdot 76^{*}$ & $(1 \cdot 75,10 \cdot 40)$ \\
\hline $45-64$ & 44 & 9.53 & $4 \cdot 62^{*}$ & $(3 \cdot 35,6 \cdot 20)$ \\
\hline $65-74$ & 43 & $24 \cdot 89$ & $1.73^{*}$ & $(1.25,2 \cdot 33)$ \\
\hline 75-84 & 54 & $36 \cdot 27$ & $1.49 *$ & $(1 \cdot 12,1 \cdot 94)$ \\
\hline $85+$ & 15 & 19.65 & 0.76 & $(0.43,1 \cdot 26)$ \\
\hline All ages & 162 & 91.60 & $1 \cdot 77^{*}$ & $(1.51,2.06)$ \\
\hline \multicolumn{5}{|l|}{ Men: } \\
\hline $15-44$ & 10 & $3 \cdot 05$ & $3 \cdot 28^{*}$ & $(1.57,6.03)$ \\
\hline $45-64$ & 51 & $21 \cdot 19$ & $2 \cdot 41^{*}$ & $(1 \cdot 79,3 \cdot 16)$ \\
\hline $65-74$ & 76 & $46 \cdot 85$ & $1 \cdot 62^{*}$ & $(1 \cdot 28,2 \cdot 03)$ \\
\hline $75-84$ & 60 & $47 \cdot 16$ & $1 \cdot 27$ & $(0.97,1.64)$ \\
\hline $85+$ & 10 & $20 \cdot 77$ & $0 \cdot 48^{*}$ & $(0.23,0.89)$ \\
\hline All ages & 207 & $139 \cdot 03$ & $1 \cdot 49^{*}$ & $(1.29,1.71)$ \\
\hline
\end{tabular}

* Significant at the $5 \%$ level.
Renal failure (chronic, acute, or end stage) was mentioned in $29(8 \%)$ death certificates. Certificates that mentioned renal failure were more likely to mention diabetes $(66 \% v 58 \%)$, but this was not significant. Significantly more certificates that mentioned renal failure (11, $38 \%$ ), were allocated to DM as the underlying cause of death than those not mentioning renal failure (46, 14\%; Fisher's exact test, two-tail $\mathrm{p}=0.00183$ ). Hypoglycaemia was mentioned on two death certificates (one man, one woman). In each case hypoglycaemia was listed as cause ia, resulting from an insulin overdose. Underlying causes of both deaths were external causes, with one case assigned a coroner's verdict of suicide and the other misadventure. The distribution of causes of death in relation to sex is shown in figure 2. There were $10(3 \%)$ deaths due to cancer of the pancreas (ICD9 rubrics 157) - five in men and five in women. In two cases, examination of the medical notes suggested that DM had developed as a result of pancreatic cancer. Ischaemic heart disease accounted for $146(40 \%)$ deaths, cerebrovascular disease for $38(10 \%)$, neoplasms for $51(14 \%)$, and external causes for $13(4 \%)$. Of the $57(15 \%)$ deaths due to $\mathrm{DM}, 25(15 \%)$ were in women and $32(15 \%)$ in men.

The SMRs for all causes of death are shown by age and sex in table 2 . Men and women have significantly raised SMRs compared with the Leicestershire population overall and for all ages under 75 years. Women also have a significantly raised SMR for the age group $75-84$ years and men have a significantly reduced SMR for age group $85+$ years.

Ischaemic heart disease was the most common cause of death. It accounted for $38 \%$ of female and $41 \%$ of male mortality. The overall SMRs $(95 \%$ CI) were $2.68(2.05,3.44)$ for women and $1.92(1.53,2.37)$ for men (table 3). For women, the main excess was observed in the age group 45-64 years, with an SMR $9 \cdot 69(5 \cdot 84,15 \cdot 10)$ and 19 deaths. For both men and women, the SMR was significantly raised in all age groups from 45 to under 85 years.

Cerebrovascular disease accounted for 38 $(10 \%)$ deaths $-22(14 \%)$ in women and 16 $(8 \%)$ in men. The SMRs for men $(2.90(1.33$, $5 \cdot 50)$ ) and women $(3 \cdot 17,(1 \cdot 37,6 \cdot 25))$ aged 65-74 were significantly raised, and the overall SMR for women was also raised $(1 \cdot 76(1 \cdot 10$, $2 \cdot 66)$ ). A total of 13 deaths were allocated Ecodes as causes - nine in women and four in men. SMRs for women were significantly raised overall $(5 \cdot 01(2 \cdot 29,9 \cdot 51))$ and in the age bands 
Table 3 Age and sex specific standardised mortality rates (SMRs) for deaths from ischaemic heart disease

\begin{tabular}{lccll}
\hline Age group & Observed deaths & Expected deaths & $S M R$ & $(95 \%$ CI $)$ \\
\hline Women: & & & & \\
$15-44$ & 0 & $0 \cdot 04$ & - & - \\
$45-64$ & 19 & $1 \cdot 96$ & $9 \cdot 69^{*}$ & $(5 \cdot 84,15 \cdot 10)$ \\
$65-74$ & 18 & $6 \cdot 94$ & $2 \cdot 59^{*}$ & $(1 \cdot 54,4 \cdot 10)$ \\
$75-84$ & 20 & $9 \cdot 94$ & $2 \cdot 01^{*}$ & $(1 \cdot 23,3 \cdot 11)$ \\
$85+$ & 4 & $3 \cdot 87$ & $1 \cdot 03$ & $(0 \cdot 28,2 \cdot 65)$ \\
All ages & 61 & $22 \cdot 75$ & $2 \cdot 68^{*}$ & $(2 \cdot 05,3 \cdot 44)$ \\
Men: & & & & \\
$15-44$ & 1 & $0 \cdot 35$ & $2 \cdot 86$ & $(0 \cdot 07,15 \cdot 90)$ \\
$45-64$ & 22 & $8 \cdot 55$ & $2 \cdot 57^{*}$ & $(1 \cdot 61,3 \cdot 90)$ \\
$65-74$ & 31 & $16 \cdot 24$ & $1 \cdot 91^{*}$ & $(1 \cdot 30,2 \cdot 71)$ \\
$75-84$ & 28 & $14 \cdot 74$ & $1 \cdot 90^{*}$ & $(1 \cdot 26,2 \cdot 75)$ \\
$85+$ & 3 & $4 \cdot 42$ & $0 \cdot 68$ & $(0 \cdot 14,1 \cdot 98)$ \\
All ages & 85 & $44 \cdot 29$ & $1 \cdot 92^{*}$ & $(1 \cdot 53,2 \cdot 37)$ \\
\hline
\end{tabular}

* Significant at the $5 \%$ level. current study, ischaemic heart disease, cerebrovascular disease, and neoplasms accounted for $63 \%$ of deaths compared with $64 \%$ due to the same causes for the Leicestershire population in 1991. The cause specific distribution differed appreciably, with excess ischaemic heart disease and cerebrovascular disease and reduced neoplastic mortality for those with diabetes. The differing age structure of the population with insulin treated diabetes compared with the background population may explain these differences. Calculation of SMRs shows that there are excess deaths in the population with insulin treated diabetes after allowing for varying age and sex distributions. Most of this excess can be explained by ischaemic heart disease for men and a combination of ischaemic heart disease and cerebrovascular disease for women.

In this study, an estimated excess mortality of $50 \%$ was found for men and one of $80 \%$ for women. Differing methods and sample compositions necessitate caution in interpretation of comparisons with other studies reporting higher or lower excesses. ${ }^{49-1118}$ Raised SMRs were found for ischaemic heart disease for men and women in all age groups from 45 to 84 years, for cerebrovascular disease for women overall but not for men. There was a significant excess in cerebrovascular disease mortality for men and women aged $65-74$ years. The raised all cause SMRs observed can be explained by these ischaemic heart disease and cerebrovascular disease excesses. While the SMRs for all neoplasms were less than 1.0 for men and for women in all age groups except ages 45-64 years, none of these decreases was significant, nor were they sufficient to counter balance the ischaemic heart disease excesses, as has been reported previously for men. ${ }^{4}$

There was an excess of deaths entered as Ecodes for women - nine deaths occured at ages less than 75 years. This has not been reported in previous epidemiological studies and could be an area for future audit and research.

This study focused on insulin-treated DM, a group comprising both IDDM and NIDDM. The age, duration of disease, and causes of mortality distributions differed between the IDDM and NIDDM groups. The IDDM group comprised only $5 \%$ of the total mortality, 18 deaths over 3 years. While it is important to bear in mind the differences, the very small numbers of IDDM make separate analyses redundant without considerably more years' worth of data. Using just NIDDM in the analyses made very little difference to the SMR estimates. Despite reported improvements in prognosis for people with diabetes ${ }^{18-20}$ those with insulin-treated DM still experience high mortality compared with the general population. Most of the excess deaths are attributable to vascular diseases. Future analyses when mortality data for more years are available should enable time trends to be described, for different ethnic groups and for different durations of diabetes.

The use of record linkage and local population based registers has been shown to be effective in estimating mortality in the popu- 
lation with diabetes. While this study has focused on insulin treated DM, the methods described are applicable to the whole population with diabetes where appropriate computerised records are available. Similarly, record linkage techniques could be used in other areas where suitable data exist. Focusing on end points other than mortality, purchasers may find uses for record linkage and local registers in identifying high risk groups and monitoring health care delivery and achievement of targets.

We thank Leicestershire Health for funding the diabetes registe and Janet Jones and Beverley Ward for their invaluable contribution to its upkeep.

1 Green A, Hougaard P. Epidemiological studies of diabetes mellitus in Denmark: 5. Mortality and causes of death among insulin-treated diabetic patients. Diabetologia 1984, 26:190-4.

2 Whittall DE, Glatthaar C, Knuiman MW, Welborn TA Deaths from diabetes are under-reported in national mortality statistics. Med $\mathcal{F}$ Aust 1990;152:598-600.

3 Fuller JH, Elford J, Goldblatt P, Adelstein AM. Diabetes mortality: new light on an underestimated public health mortality: new light on an underestim

4 problem. Diabetologia 1983;24:336-41. Narayan V. Mortality in diabetes mellitus: experience of Narayan V. Mortality in diabetes mellitus: experience of

5 Ochi JW, Melton III LJ, Palumbo PJ, Chu C. A populationbased study of diabetes mortality. Diabetes Care 1985;8: 224-9.

6 Moss SE, Klein R, Klein BEK. Cause-specific mortality in population-based study of diabetes. Am 7 Public Healt 1991;81:1158-62.
7 Walker JB. Chronicle of a diabetic service. London: The British Diabetic Association, 1989

$8 \mathrm{McNally} \mathrm{PG,} \mathrm{Burden} \mathrm{AC,} \mathrm{Swift} \mathrm{PGF,} \mathrm{Walls} \mathrm{J,} \mathrm{Hearnshaw}$ $\mathrm{JR}$. The prevalence and risk factors associated with the onset of diabetic nephropathy in juvenile-onset (insulindependent) diabetics diagnosed under the age of 17 years in Leicestershire 1930-1985. Q $\mathcal{F}$ Med 1990;280:831-44.

9 Nystrom L, Ostman J, Wall S, Wibell L, DISS Group. Mortality of all incident cases of diabetes mellitus in Sweden diagnosed $1983-1987$ at age 15-34 years. Diabetic Med 1992;9:422-7.

10 Dorman JS, LaPorte RE, Kuller LH et al. The Pittsburgh insulin-dependent diabetes mellitus (IDDM) morbidity and mortality study: mortality results. Diabetes 1984;33: 271-6.

11 Kleinman JC, Donahue RP, Harris MI, Finucane FF, Madans $\mathrm{JH}$, Brock DB. Mortality among diabetics in a nadans JH, Brock DB. Mortality among diabetics in

12 Sprafka JM, Pankow J, McGovern PG, French LR. Mortality among type 2 diabetic individuals and associated tality among type 2 diabetic individuals and associated risk fact $627-33$.

13 Langley JD, Jackson D, Botha JL. The Leicestershire mortality list: A population-based mortality information system. F Epidemiol Community Health 1994;48:A509.

14 Langley JD, Botha JL. Use of record linkage techniques to maintain the Leicestershire diabetes register. Computer Methods and Programs in Biomedicine 1994;41:287-95.

15 SAS Institute Inc. SAS language reference. Version 6. 1st ed. Cary, NC: SAS Institute Inc, 1990.

16 Gardner MJ, Gardner SB, Winter P. Confidence interval analysis (CIA). Version 1.2. London; BMJ Publishing Group, 1991 .

17 MacLeod JM. Death certificates and diabetes. Diabetic Med 1993;10(suppl):S33.

18 Sartor G, Nystrom L, Dahlquist G. The Swedish childhood diabetes study: a seven-fold decrease in short-term mordiabetes study: a seven-fold decrease
tality. Diabetic Med 1990;8:18-21.

19 Borch-Johnsen K, Kreiner S, Deckert T. Mortality of type 1 (insulin-dependent) diabetes mellitus in Denmark: a study of relative mortality in 2930 Danish type 1 diabetic patients diagnosed from 1933 to 1972. Diabetologia 1986; 29:767-72.

20 Green A, Borch-Johnsen K, Anderson PK et al. Relative mortality of Type 1 (insulin-dependent) diabetes in Denmark: 1933-1981. Diabetologia 1985;28:339-42. 